\title{
Promoting a Growth Mindset in CS1: Does One Size Fit All? A Pilot Study
}

\author{
Keith Quille \\ Dept. of Computing \\ TU Dublin \\ Tallaght, Dublin, Ireland \\ Keith.Quille@TUDublin.ie
}

\author{
Susan Bergin \\ Dept. of Computer Science \\ Maynooth University \\ Co Kildare, Ireland \\ Susan.Bergin@MU.ie
}

\begin{abstract}
This paper describes a pilot intervention conducted in CS1, in the academic year of 2016-2017. The intervention was based on the work of Dweck, promoting a growth Mindset in an effort to increase performance in introductory programming. The study also examined data from a previous year (as a control group) to compare and contrast the results. Multiple factors related to programming performance were recorded with the control and treatment group, which were measured at multiple intervals throughout the course, to monitor changes as the pilot intervention was implemented.

This study found a significant increase in programming performance when the intervention was deployed. However, although performance increased for the treatment group, the average Mindset did not significantly change towards a growth Mindset (replicating the findings of Cutts et al, 2010). To further explore this finding, a preliminary deeper investigation using k-means clustering was carried out. The investigation found that the intervention promoted a growth Mindset for some student profiles and a fixed Mindset for others. This finding is important for educators considering intervention development or implementation of Mindset, and demonstrates that a Mindset intervention may not be suitable for all learners.
\end{abstract}

\section{CCS CONCEPTS}

- Social and professional topics $\rightarrow$ Computer science education; CS1.

\section{KEYWORDS}

Introductory Programming; CS1; Intervention; Growth Mindset; Clustering; K-Means; Self-Efficacy; Replication Study

\section{ACM Reference Format:}

Keith Quille and Susan Bergin. 2020. Promoting a Growth Mindset in CS1: Does One Size Fit All? A Pilot Study. In Proceedings of the 2020 ACM Conference on Innovation and Technology in Computer Science Education (ITiCSE '20), June 15-19, 2020, Trondheim, Norway. ACM, New York, NY, USA, 7 pages. https://doi.org/10.1145/3341525.3387361

Permission to make digital or hard copies of all or part of this work for personal or classroom use is granted without fee provided that copies are not made or distributed for profit or commercial advantage and that copies bear this notice and the full citation on the first page. Copyrights for components of this work owned by others than ACM must be honored. Abstracting with credit is permitted. To copy otherwise, or republish, to post on servers or to redistribute to lists, requires prior specific permission and/or a fee. Request permissions from permissions@acm.org.

ITiCSE '20, June 15-19, 2020, Trondheim, Norway

(C) 2020 Association for Computing Machinery.

ACM ISBN 978-1-4503-6874-2/20/06 . \$ $\$ 15.00$

https://doi.org/10.1145/3341525.3387361

\section{INTRODUCTION}

Computer Science Education (CSEd) in Ireland, has typically one of the highest attrition rates of all third level courses, consistently for the past decade $[22,30]$. This high attrition rate is echoed in many other jurisdictions [2]. Learning to program is often attributed or considered a core cause for this attrition, among tertiary level teachers and researchers [2,26]. While it is well acknowledged that a number of models exist to identify students who are at risk of dropping out or failing, there is a shortfall in further development into interventions or practices in the class room targeting attrition rates.

This is highlighted by a call from the ITiCSE ' 15 working group [19], which identifies several grand challenges, one of which is: "Drop-out risk and performance, which identifies students who are at risk of dropping out, have been studied to an extent, but have not been employed to create actual interventions where some of the proposed methods would be put into practice. We believe that theoretical results are important, but that in this field their real value comes from application". The fourth Grand Challenge is "to adopt results and practices into classroom use to continuously monitor and improve offered education." [19]. At our institutions numerous interventions have been examined, including: introducing Scratch in parallel to CS1 to improve self-efficacy and performance [34, 38]; using automated assessment in CS1 [44]; using neuro-feedback system to promote engagement [23]; and facilitating large class sizes and interventions [31].

These are valuable pieces of work, with varying degrees of success. Each intervention however, requires specific tools or methodologies to be implemented and the outcome does not directly implicate a wide range of other subjects or modules. An intervention such as promoting a growth Mindset alleviates this limitation as it is transferable to other domains. In addition the promotion of a growth Mindset is now becoming common practice in primary and second level education [4]. This perhaps concurrent practice may have long term benefits for students [9], but is outside the scope of this paper to report on.

\section{RELATED LITERATURE}

Dweck has plausibly established that a person's Mindset about their ability can impact their performance [8]. More specifically, she developed the idea of two Mindset types, growth and fixed Mindset. Ehrlinger et al [10], describe Mindset as: "Believing that one's qualities are carved in stone (an entity theory or fixed Mindset) activates the motivation to prove oneself over and over. If intelligence or competence is a fixed quality, it becomes important to prove-to oneself and others that one has that quality in spades. Research shows 
that people with a fixed Mindset will go to great lengths to feel or appear successful, even if it sometimes involves cheating. If they are not successful, people with the fixed Mindset may engage in a variety of defensive behaviours to hide this. Above all, they want to have "the right stuff". In contrast, some people believe that where they start is just the beginning of their development. While some may start with an advantage or disadvantage, a growth Mindset suggests that all people can change and develop by applying effort and gaining experience. Thus, people who subscribe to a growth Mindset are more willing to make mistakes or appear foolish in the short run in the service of maximising their development over time."

There appears to be very little literature on Mindset intervention during introductory programming courses, especially at third level and the studies available have reported mixed results. For example, Cutts et al. conducted a study on a CS1 class, based on Dweck's Mindset research. Combinations of three interventions were carried out: tutors taught Mindset to students; growth Mindset feedback messages were given to students on their work; and, when stuck, students were given guided pathways (cheat-sheets) to solve the problem. The study reports that although Mindset did not change significantly, there was a positive change in performance. Cutts et al. put forward (both from their experiences and literature) that students in introductory programming tend to change towards a fixed Mindset during the course due to the very high number of potential error points in programming [6].

A study by Simon et al. attempted a "saying is believing" intervention [43] to encourage CS1 students to adopt a growth Mindset both in general and towards programming. The study (where the study spanned three institutions) reported no significant findings while employing their Mindset intervention. However it must be noted that the intervention exposure was very minimal (a single lecture and a one page handout reminder), which was noted and outlined in future work, by Simon et al. [43]. This suggests that disparate, one off sessions may not be as effective as integrating the intervention into the culture of the lectures.

Flanigan did not employ an intervention, but measured Mindset across the semester and reported "for all students, there were significant increases in fixed Mindset and significant decreases in growth Mindset across the semester. However, results showed that students had higher scores for growth Mindset than fixed Mindset at both the beginning and end of the semester". Flanigan also reported that student Mindset was a weak predictor of performance [14].

Kaijanaho found that there was little to no correlation between Mindset and performance in CS courses (these courses were advanced CS courses) [20]. Kaijanaho concluded: "This suggests that any effect the Mindset has on the outcomes of these courses is small. We conclude that educational interventions targeting students' Mindsets may not be worth the effort in late bachelor-level CS education".

Gorson conducted an interview study, and found that CS students interview answers generally did not align with Mindset theory. Many participants either included both fixed and growth attributes or misaligned with their associated behaviours [17].

Outside of CS1, Miller discusses a large scale study with mixed results [28]. However Miller noted that the intervention did not improve all grades equally: "Here we show that a short (less than one hour), online growth Mindset intervention ... improved grades among lower-achieving students and increased overall enrolment to advanced mathematics courses". This suggests that Mindset interventions may affect sub-groups of students differently.

Dweck and Yeager, in 2019 reflected on two eras of research [9], discussing early work up to and including recent large scale studies and interventions. Yeager discusses more recent large scale studies [32, 49] (with two replication studies [9]), reporting again that the intervention effects on academic performance apply to some sub-cohorts more than others, in this case low achieving students reported the most positive effects. In all cases reported the performance increase was minor (with effect sizes typically less than 0.2 SD [15]). Finally the authors state: This may sound strange to say after decades of research, but we still know far too little about how best to transmit a growth Mindset to individuals, how contexts determine whether students take up and apply a new Mindset, or how to help embed a growth Mindset in the cultures of schools. Research into these issues is critical because we have learned that it is too easy for people to implement a growth Mindset poorly.

Overall the literature reports mixed outcomes for CS1 Mindset interventions at third level. This perhaps is due to the limited exposure that students have received, or the depth of the investigations (only measuring Mindset vs performance for example). The largest introductory programming intervention reported on was four consecutive weeks, which had some success [6]. If an intervention was run for the entire semester (12-14 weeks), would the literature report the same responses? In addition, could a deeper analysis uncover relationships undetectable at a high level, that just recorded Mindset and performance.

\section{RESEARCH QUESTIONS}

Two research questions are considered in this pilot study:

(1) Can an intervention promoting a growth Mindset, improve performance in an introductory programming course?

(2) Does promoting a growth Mindset have the same affect on all students, or are certain student cohorts affected differently?

RQ1 is founded on the work of Cutts et al. [6] as they implemented a similar intervention. While the methodology of this study and the study conducted by Cutts et al. differ somewhat (student exposure to the intervention), a goal of RQ1 is to re-validate the work of Cutts et al. while also examining the effects of the intervention in an Irish context. RQ2 is founded on the work of Yeager [32, 49] who reported that the intervention effects apply to some student subcohorts more than others. Thus, RQ2 aims to investigate the Mindset changes on student sub-groups using clustering techniques.

\section{DATA COLLECTION AND POPULATION}

\subsection{Data Collection}

During the academic year 2016-17, two institutions participated in this study (with $n=46$ participants). Both institutions also participated in a study conducted in the previous year $(n=55)$ which is used as the control group [36]. The data collection techniques and the factors collected (along with factor details) of the control data-set are presented in the the references [36, 38, 39]. This allowed the authors compare the control student population (with no intervention) to the current cohort to examine the effectiveness of the intervention. In addition the two populations were also 
compared (pre-intervention), to investigate if any differences existed that may account for variance (if any) in the affect of the intervention (Section 4.2).

The two institutions consisted of a Community College and a University. The data collection process and analysis techniques were identical to two previous studies as described in [36, 39] allowing for comparison of the control and treatment groups. The Mindset survey was adopted from the work of Dweck [8], by D'Anca [7] which was included in this study. The only other difference to the previous studies, was that the surveys were conducted at three stages through out the academic year. Initially before the intervention was deployed (stage one, at approximately $10 \%$ into the delivery of CS1), at the end of CS1 (stage two, in semester 1 before the examinations) and at the end of the academic year (stage three, at the end of CS2 in semester 2, before the examinations). This allowed the authors to track changes in attributes such as Mindset and programming self-efficacy over the entire academic year. The survey was optional which coupled with absenteeism meant that not all students, participated in all stages. When analysing one or more stages, only students who were present in all stages investigated are presented and the the associated sample size is reported.

\subsection{Population Analysis}

Before the intervention results were analysed, the control cohort of students from 2015-16 were compared to this studies intervention student cohort. This was conducted at stage one, before the intervention was applied. This was to examine if any affects of the intervention could be attributed to pre-existing differences between the cohorts and not as a result of the intervention. The survey questions/factors, (their design design and validation) were taken from a longitudinal study which developed a model to predict success $[33,35,36,38,39]$, where the factors (or combinations of the factors) have been shown to be indicative of success in CS1. Thus if significant differences were found in these factors between groups, they may be attributed to the affect of this intervention (if any was reported).

It must be noted the both institutions were delivering the exact same course for both years, with no additional interventions or teaching methodologies applied. Also the same lecturer, lectured in both institutions to both groups of students (both years), thus considerably reducing differences associated with different lecturer delivery methods or the lecturer themselves as a contributor to any difference in performance or Mindset changes [29]. A Welch's unequal variances t-test [45] was used to examine if any statistically significant differences existed between both student cohorts using the 12 factors collected. The results presented in Table 1 also report the mean for each cohort data-set and show that other than Gender balance (2015-16, $n=2$ female students compared to this study which consisted of $n=6$ female students), no statistically significant differences existed between the two cohorts.

\section{METHODOLOGY}

Stage one to stage two, was where the pilot intervention was applied. This consisted of several approaches to promote a growth Mindset.
Table 1: Comparison of the two student cohorts averages and Welch's $t$-test $p$-values, at Stage one, pre-intervention.

\begin{tabular}{|l|c|c|c|c|}
\hline Factor & $\mathbf{2 0 1 5 - 1 6}$ & $\mathbf{2 0 1 6 - 1 7}$ & $\boldsymbol{p}$-value & SS \\
\hline Programming Self-Efficacy & -0.3295 & 0.2429 & 0.0500 & $\mathrm{~N}$ \\
\hline Predicted End of Year Grade & $76.72 \%$ & $77.71 \%$ & 0.6989 & $\mathrm{~N}$ \\
\hline Gender Balance & $3.64 \%$ & $13.04 \%$ & $<0.0000$ & $\mathrm{Y}$ \\
\hline Age (years) & 26.45 & 28.95 & 0.2145 & $\mathrm{~N}$ \\
\hline Maths Grade Normalised & 6.8 & 6.15 & 0.2888 & $\mathrm{~N}$ \\
\hline Maths Grade Raw & $65.78 \%$ & $64.69 \%$ & 0.7548 & $\mathrm{~N}$ \\
\hline Playing Computer Games (h) & 1.49 & 1.26 & 0.5330 & $\mathrm{~N}$ \\
\hline Time to Complete Survey (s) & 440.15 & 433.88 & 0.8322 & $\mathrm{~N}$ \\
\hline Condesco & 9.21 & 8.97 & 0.6063 & $\mathrm{~N}$ \\
\hline Intrinsic Goal Orientation & 21.65 & 21.02 & 0.3996 & $\mathrm{~N}$ \\
\hline Test Anxiety & 21.2 & 22.02 & 0.5180 & $\mathrm{~N}$ \\
\hline Hours Spent on Social Media & 1.89 & 1.56 & 0.3827 & $\mathrm{~N}$ \\
\hline \multicolumn{2}{|c|}{ SS = Statistically Significant with a confidence interval (CI)=95\% } \\
\hline
\end{tabular}

The methodology was developed from previous work [6, 8, 25, 30] and is composed of three parts:

Dedicated lecture time: Time was dedicated to the intervention at the start of each session (4 hour session) and lasted generally for five to ten minutes. The focus was on promoting the fundamentals of developing a growth Mindset, and the impact to which it has been reported to have on performance in other domains (such as kindergarten and at the second level). This is reported to be more effective than teaching both growth and fixed Mindsets at the same time [9]. The lecturer used their own personal experiences and relayed the correlation between work ethic (grit [42]) and performance. The lecturer also presented testimonials from students who had completed the course, especially students who initially struggled. This was conducted for all 12 weeks from stage one to stage two.

Research: In addition to the lectures, at approximately each quarter of the course delivery, case studies were presented to the students with scientific findings (in contrast to qualitative). This was drawn from Dweck's work, the related literature $[8,9]$ and neuroscience [27]. This aimed to further target students with a fixed Mindset, who believe that they cannot improve and who may disbelieve the findings presented in the lectures. An example of this was research on neuroplasticity [1, 41].

Feedback: Feedback was delivered regularly during the programming labs, but also formally after assessment. The main goal of the feedback was to praise the process, not the person. In addition, if the feedback was on a poor result, it was delivered in a constructive manner identifying the processes that the student needed to do, to achieve a stronger result.

\section{INTERVENTION RESULTS}

This section discusses three sets of results. Firstly, it examines if the pilot intervention had an affect on CS1 performance between the control and treatment groups (in response to Research Question 1). Secondly, this section examines if the intervention positively promoted a growth Mindset in CS1. Finally, it examines the changes 
in programming self-efficacy over the course of the intervention and CS1, and if any correlation exists between Mindset, self-efficacy and performance.

\subsection{CS1 Performance}

The results as presented in Table 2 are statistically significant. The 2015-16 cohort had a pass rate of $41.81 \%$, and the study cohort (with the Mindset intervention), had a pass rate of $69.57 \%$. In addition the differences in raw CS1 grades (in percentage) were also statistically significant. This is a significant increase in performance given that the only underlying population difference was the small increase in the ratio of female students in the intervention cohort.

Table 2: Comparison of the two student cohorts results and Welch's $t$-test $p$-values, at the end of CS1 (stage two)

\begin{tabular}{|l|c|c|c|c|}
\hline Performance Measure & $\mathbf{2 0 1 5 - 1 6}$ & $\mathbf{2 0 1 6 - 1 7}$ & $\boldsymbol{p}$-value & SS \\
\hline Raw Results & $66.71 \%$ & $75.39 \%$ & 0.0197 & $\mathrm{Y}$ \\
\hline Pass/Fail Rates (dichotomous) & $41.81 \%$ & $69.57 \%$ & $<0.0001$ & $\mathrm{Y}$ \\
\hline \multicolumn{2}{|c|}{ SS = Statistically Significant with a confidence interval (CI) $=95 \%$}
\end{tabular}

As discussed in the literature by Miller [28], effect size is a quantitative measure of the magnitude of a phenomenon [21]. Miller reports that some Mindset interventions have a treatment reported effect size less than $0.1 \mathrm{SD}$, with one such study reporting an effect size of $\approx 0.05$ SD implementing a one hour online growth Mindset intervention [46]. Miller also discusses a study looking at educational distributions of treatment effects from educational evaluation trials [24], and suggests a SD of 0.2 for effect size. This value aligns with the context-free effect size guidelines which reported 0.20 SDs [15]. The SD of the raw CS1 results of the 2015-16 (where no intervention was applied) was 15.18. Thus the increase in performance was 0.57 SD. This effect size is notable in comparison to other interventions as reported by Miller [28].

\subsection{Promoting a Growth Mindset During CS1}

There was an overall slight increase in Mindset from stage one to stage two. The Mindset values were taken as per the Mindset survey by D'Anca [7], with value ranges presented in Table 3. The average Mindset value in stage one was 41.69 (where higher values correlate to a Growth Mindset). The average of stage two Mindset was $43.03(n=24)$. This increase was not statistically significant (using a Welch's t-test reporting a $p=0.0613$ ).

Table 3: Mindset Values from D’Anca's Survey

\begin{tabular}{|l|c|}
\hline Mindset & Survey Value \\
\hline Strong Growth Mindset & $45-60$ \\
\hline Growth Mindset with some Fixed ideas & $32-44$ \\
\hline Fixed Mindset with some Growth ideas & $21-33$ \\
\hline Strong Fixed Mindset & $0-20$ \\
\hline
\end{tabular}

\subsection{Programming Self-Efficacy During CS1}

Additionally, the change in programming self-efficacy, from stage one to stage two was reviewed $(n=20)$. While multiple studies examine self-efficacy, it is seldom tracked at regular intervals across CS1. A trend line for self-efficacy from stage one to stage two was generated (Figure 1). Students with high positive programming self-efficacy in stage one reduce at stage two, while students with very low programming self-efficacy in stage one increase in stage two, with students in the middle showing little to no change. This is interesting and was explored further. With the data reduction techniques used in the self-efficacy question [36,37], a negative value represents a high programming self-efficacy and a positive value represents a low programming self-efficacy. The results may be in part be caused by students who overrate their programming self-efficacy in stage one, view it more realistically at stage two (reduction), and students who underrate their programming selfefficacy (such as female or older students [35, 39]), rate it more realistically at stage two (increase).

Figure 1: Changes in programming self-efficacy from stage one to stage two, with a trend line to show average changes

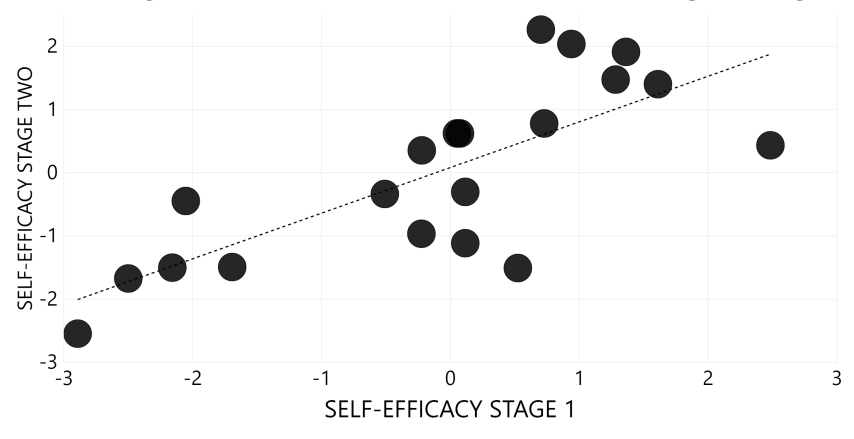

\subsection{Correlation with Performance}

Next Pearson correlation coefficient's were examined. It is well acknowledged that programming self-efficacy is a good predictor of success with relatively strong correlation values $[3,35,36]$. The Pearson correlation coefficient's for Mindset and performance was only $r=0.4$, whereas programming self-efficacy and programming was $r=-0.7$ (negative due to the data reduction technique). This suggests that Mindset at stage one, is not a good predictor of performance (as reported in the literature [14]). When Mindset and programming self-efficacy were calculated, this reported an even poorer correlation at just $r=-0.3$.

\subsection{Results Conclusion}

A very positive initial finding was that the performance of the treatment cohort was significantly higher than the control group. Programming self-efficacy changes differently for different cohorts, and while self-efficacy is not temporally stable, it perhaps justifies further investigation into both self-efficacy and Mindset (as this construct may exhibit similar trends). This finding (addressing RG1) replicates that of Cutts et al. [6] where the overall performance of the students improved and the average Mindset of the students exposed to the intervention did change towards a growth Mindset, but did not change significantly. If the pedagogy of CS1 was identical for both groups (excluding the intervention), and the intervention was successful in improving the performance, it would therefore follow that the Mindset values would have been perhaps modified 
in some significant way. As all of the literature seems to stop here, RG2 contributes to the CS Mindset space by examining this phenomena in more detail, in the following section, using clustering techniques.

\section{FURTHER ANALYSIS USING CLUSTERING}

With high level analysis, such as mean values or regression, sometimes the entire story may not be visible. Clustering of the data may help uncover relationships, not clearly visible using high level analysis techniques. This section reports on preliminary analysis using automatic clustering to investigate if any sub-cohorts of students were affected differently (or grouped differently) by the intervention, (in response to RQ2). The clustering algorithm implemented was k-means, and the number of clusters were automatically determined by the mean of five unsupervised methods. These method's included: explainWSS ${ }^{1}$, robustElbow ${ }^{2}, \mathrm{db}^{3}$, ratkowsky ${ }^{4}$ and ball ${ }^{5}$ $[5,16]$. While this analysis is only in it's pilot phase, some initial interesting findings emerged and are presented in the following subsections.

\subsection{Age and Mindset During CS1}

The clustering of age and change in Mindset (stage one to stage two) was conducted. This resulted in three clusters, where the average age and average change in Mindset for each cluster was graphed and a trend line was added (as presented in Figure 2). This graph $(n=24)$ clearly shows that younger students experience a positive change in Mindset (towards growth), whereas older students (over $\approx 28$ years of age), in-fact migrate towards a fixed Mindset at a steeper rate. Although these differences are not statistically significant (using a one-way ANOVA analysis reporting $\mathrm{F}(2,21)=1.233$, $p$-value $=$ 0.3116 ), this is concerning as this suggests that the intervention may not work for older mature students or worse, may have a negative impact. Yeager reports that adolescents are notoriously resistant to adults' efforts to change them [47], this finding suggests that CS1 students may react differently to the intervention, than their peers in other domains and additional research is required to investigate this further.

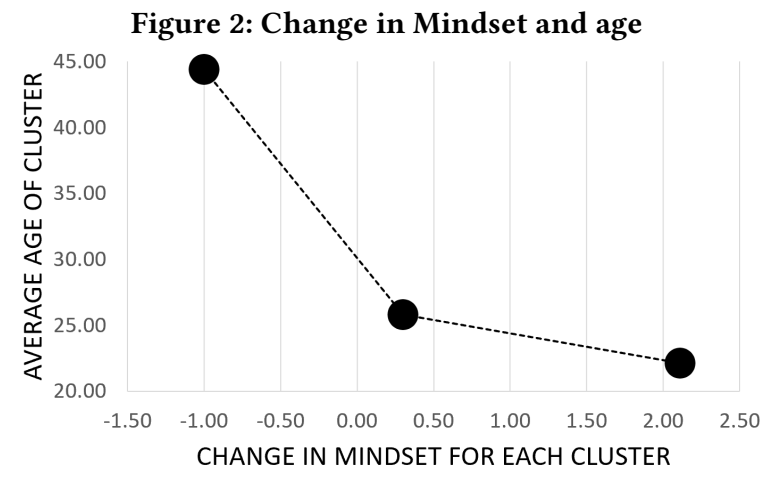

\footnotetext{
${ }^{1}$ explainWSS: Within cluster Sum of Square

${ }^{2}$ robustElbow: The elbow method

${ }^{3} \mathrm{db}$ : Davies-Bouldin index (DBI), Davies and Bouldin from 1979

${ }^{4}$ ratkowsky: Ratkowsky and Lance method from 1978

${ }^{5}$ ball: Ball and Hall method 1965
}

\subsection{Change in Mindset and Programming Self-Efficacy Over CS1, Clustered by Performance}

As reported in Section 6.3 and Section 6.4, self-efficacy and Mindset as a construct do not correlate strongly and perhaps affect different learners in different ways. In this section, clusters based on the change in programming self-efficacy between stage one and two, the change in Mindset between stage one and two and CS1 performance taken at stage two (the performance was grouped into Low, Middle and High performers) were constructed. Both Y axis variables show increases in the same direction (the self-efficacy is reversed to show positive increase). Three clusters were returned $(n=20)$ and are presented in Figure 3.

Figure 3: Changes in programming self-efficacy and Mindset over CS1, clustered by performance

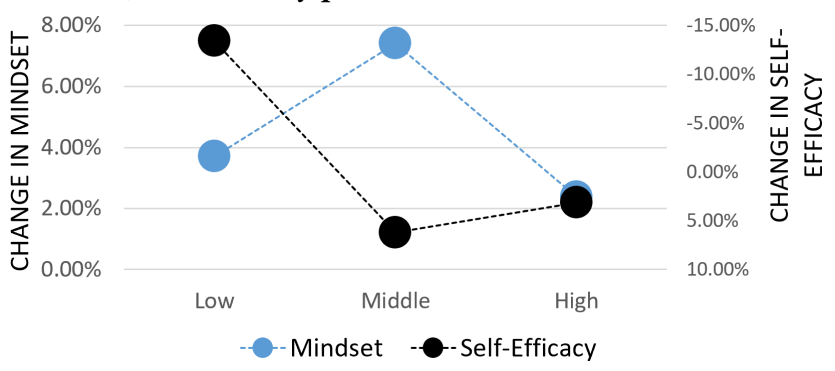

7.2.1 Low performing students: reported the largest positive change in programming self-efficacy while experience a positive change in Mindset (agreeing with the literature). This is very valuable as it would be acknowledged that these students are in most need of such an intervention.

7.2.2 Middle performing students: reported the largest positive change in Mindset (towards growth), whereas their programming self-efficacy decreased. Perhaps as the course continued, their selfefficacy aligned to its true value (over inflated at the start) but their increase in Mindset ( $~ 8 \%)$ shows that this may be a sub-group worth targeting.

7.2.3 High performing students: reported the least amount of change in programming self-efficacy and Mindset, perhaps they are realistic about their ability, and interventions such as Mindset, have little to no value for these students, or may have value in area's other than performance [9].

\subsection{Mindset and Programming Self-Efficacy}

Findings in Section 6.4, report a correlation of -0.3 between Mindset and self-efficacy. This is somewhat disappointing as the authors anecdotally hypothesised that the two constructs are well related or perhaps even measure the same underlying phenomenon. Mindset and programming self-efficacy was clustered using k-means, with automatic cluster number identification. Three clusters were identified, where each cluster is colour coded and sorted by programming self-efficacy, as presented in Figure 4 (where a positive programming self-efficacy is a negative $\mathrm{Y}$ axis value). 
Figure 4: Programming self-efficacy and Mindset values plotted at stage one.

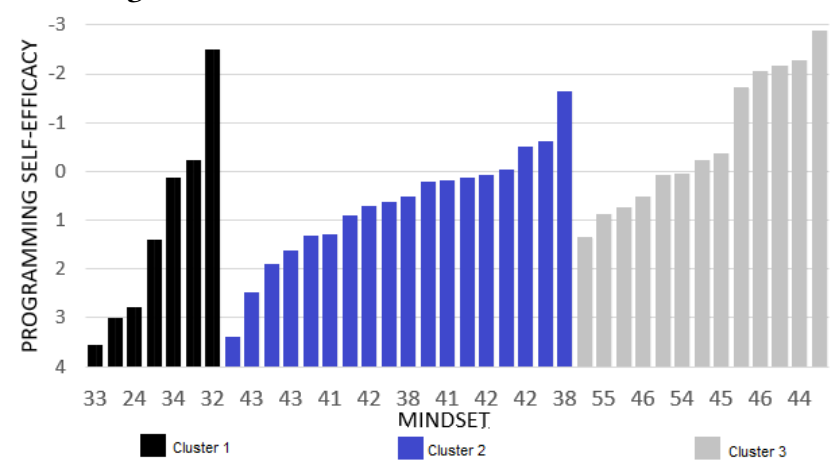

The average Mindset value for each cluster was then plotted and a trend line was added. This is presented in Figure 5. Table 3 shows that the first two cluster group's average Mindset values (32 and 41) are at the upper and lower end of "Growth Mindset with some Fixed ideas" whereas the upper cluster average Mindset value of 48 represents a "strong Growth Mindset". The results of this clustering, show a strong correlation. A Pearson correlation coefficient was calculated using the three cluster Mindset and Self-Efficacy averages, producing a value of $r=-0.944$. This shows that there is in-fact a very strong correlation between Mindset and programming self-efficacy, if the student sub-groups are clustered. Further investigation is required to unpack these clusters, and investigate the underlying cause for this multi-modal result.

Figure 5: Mindset and programming self-efficacy clustered

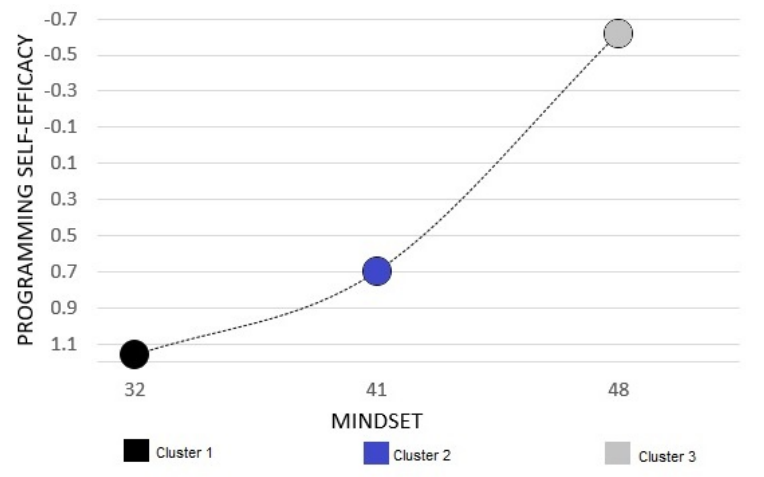

\section{THREATS TO VALIDITY}

This study has reported some interesting findings, with potential for future direction and research. As this is a pilot study, the dataset size for both the control and treatment group was relatively small. This was compounded by some students not being present for subsequent stages. Delivering the Mindset intervention itself, was also pilot in its nature. While it was founded on research, it is still in it's developmental phase. The lecturer who delivered the intervention, exhibited traits of a growth Mindset, where research has reported that this may effect the intervention itself [29], where similar effects can be seen with parents [18].
While this pilot study acknowledges this, the lecturer was the lecturer of both the control and treatment group, thus the influence of the lecturers growth Mindset should be equal to both groups. However, the threat to validity or concerns for replication studies is, if a different lecturer delivered the intervention (who exhibited fixed Mindset traits), perhaps the outcomes may be different. The intervention showed positive findings such as increases in performance. A deeper analysis using clustering, reports that the intervention effected student sub-cohorts in different ways. While this is reported in the literature, the pilot intervention did not positively effect all students, for example for older students $(>\approx 28$ years of age), where the intervention actually promoted a fixed Mindset (not by a significant amount, but towards a fixed Mindset none the less), thus further development of the intervention is required, or it's targeted sub-groups should be selected carefully.

\section{CONCLUSION}

Promoting a growth Mindset as an intervention, in introductory programming courses, resulted in a statistically significant increase in performance compared to the control cohort (however the average change in Mindset did not increase significantly). Thus answering RQ1 and replicating the findings of Cutts el al: can an intervention promoting a growth Mindset, improve performance in an introductory programming course? No statistical differences were found between the cohorts (using multiple factors indicative of performance) prior to the intervention (stage one). The treatment group outperformed the control group. This is a provisional claim, as there may be additional variables unaccounted for, and the sample size was relatively small, thus further work is justified.

Following, the initial findings, the study then examined the data using clustering techniques to determine if sub-cohorts of students experienced the intervention in different ways, thus examining RQ2: does promoting a growth Mindset have the same affect on all students, or are certain student cohorts affected differently? This study identified that the promoting a Growth Mindset, may affect different cohorts of students in different ways. One example was the affect of the intervention on age groups, where of concern is the intervention may have a negative affect on older students. In addition the study found the intervention had differing affects on student cohorts clustered by performance (which agrees with the literature [48]). This effect could be compounded, with a new upper second level computer science curriculum in Ireland [40] and internationally [11-13], where students may enter the course with formal prior performance, and as it is an optional subject, many students may still be entering the courses with little to no prior experience, creating a larger than seen before divide.

The Clustering analysis has preliminary shown that while the literature up to now may discount the effect of promoting a Growth Mindset, it still may be of value to the CSEd community, however one size may not fit all. Acknowledging the limitations of this work due to data set size, future work should include an additional study, with a larger cohort over a longitudinal period. In particular the insights the clustering analysis has provided could be investigated further as it seems that interventions in CS1 are perhaps more complex to implement and analyse, than first thought. 


\section{REFERENCES}

[1] J. Aronson, C. B. Fried, and C. Good. Reducing the effects of stereotype threat on african american college students by shaping theories of intelligence. Fournal of Experimental Social Psychology, 38(2):113-125, 2002.

[2] J. Bennedsen and E. Caspersen, Michael. Failure rates in introductory programming. ACM SIGCSE Bulletin, 39(2):32-36, 2007.

[3] S. Bergin and R. Reilly. Programming: Factors that influence success. SIGCSE Bull., 37(1):411-415, February 2005.

[4] B. Busch. Research every teacher should know: growth mindset, 2018.

[5] M. Charrad, N. Ghazzali, V. Boiteau, and A. Niknafs. Determining the Best Number of Clusters in a Data Set, 2015.

[6] Q. Cutts, E. Cutts, S. Draper, P. O’Donnell, and P. Saffrey. Manipulating mindset to positively influence introductory programming performance. Proceedings of the 41st ACM technical symposium on Computer science education-SIGCSE' '10, page 431, 2010.

[7] J.-A. D'Anca. MINDSET AND RESILIENCE: AN ANALYSIS AND INTERVENTION FOR SCHOOL ADMINISTRATORS. PhD thesis, 2017.

[8] C. S. Dweck. Mindset: The new psychology of success. Random House Digital, Inc., 2008.

[9] C. S. Dweck and D. S. Yeager. Mindsets: A view from two eras. Perspectives on Psychological Science, 14(3):481-496, 2019. PMID: 30707853.

[10] J. Ehrlinger, A. L. Mitchum, and C. S. Dweck. Understanding overconfidence: Theories of intelligence, preferential attention, and distorted self-assessment. Journal of Experimental Social Psychology, 63:94-100, 2016.

[11] K. Falkner, S. Sentance, R. Vivian, S. Barksdale, L. Busuttil, E. Cole, C. Liebe, F. Maiorana, M. M. McGill, and K. Quille. An international benchmark study of k-12 computer science education in schools. In Proceedings of the 2019 ACM Conference on Innovation and Technology in Computer Science Education, ITiCSE '19, page 257-258, New York, NY, USA, 2019. Association for Computing Machinery.

[12] K. Falkner, S. Sentance, R. Vivian, S. Barksdale, L. Busuttil, E. Cole, C. Liebe F. Maiorana, M. M. McGill, and K. Quille. An international comparison of k-12 computer science education intended and enacted curricula. In Proceedings of the 19th Koli Calling International Conference on Computing Education Research, Koli Calling '19, New York, NY, USA, 2019. Association for Computing Machinery.

[13] K. Falkner, S. Sentance, R. Vivian, S. Barksdale, L. Busuttil, E. Cole, C. Liebe, F. Maiorana, M. M. McGill, and K. Quille. An international study piloting the measuring teacher enacted computing curriculum (metrecc) instrument. In Proceedings of the Working Group Reports on Innovation and Technology in Computer Science Education, ITiCSE-WGR '19, page 111-142, New York, NY, USA, 2019. Association for Computing Machinery.

[14] A. E. Flanigan, M. S. Peteranetz, D. F. Shell, and L.-K. Soh. Exploring Changes in Computer Science Students' Implicit Theories of Intelligence Across the Semester. Proceedings of the eleventh annual International Conference on International Computing Education Research - ICER '15, pages 161-168, 2015.

[15] D. C. Funder and D. J. Ozer. Evaluating effect size in psychological research Sense and nonsense. Advances in Methods and Practices in Psychological Science, 2(2):156-168, 2019.

[16] I. Gialampoukidis, S. Vrochidis, and I. Kompatsiaris. Machine Learning and Data Mining in Pattern Recognition. 9729:170-184, 2016.

[17] J. Gorson and E. O. Rourke. How Do Students Talk About Intelligence ? An Investigation of Motivation, Self-efficacy, and Mindsets in Computer Science.

[18] K. Haimovitz and C. S. Dweck. Parents' views of failure predict children's fixed and growth intelligence mind-sets. Psychological science, 27(6):859-869, 2016

[19] P. Ihantola, A. Vihavainen, A. Ahadi, M. Butler, J. Börstler, S. H. Edwards, E. Isohanni, A. Korhonen, A. Petersen, K. Rivers, M. A. Rubio, J. Sheard, B. Skupas, J. Spacco, C. Szabo, and D. Toll. Educational data mining and learning analytics in programming: Literature review and case studies. In Proceedings of the 2015 ITiCSE on Working Group Reports, ITICSE-WGR '15, pages 41-63, New York, NY, USA, 2015. ACM.

[20] A.-J. Kaijanaho and V. Tirronen. Fixed versus growth mindset does not seem to matter much: A prospective observational study in two late bachelor level computer science courses. pages 11-20, 2018.

[21] K. Kelley and K. J. Preacher. On effect size. Psychological methods, 17(2):137, 2012

[22] M. Liston, D. Frawley, and V. Patterson. A study of progression in irish higher education. Higher Education Authority. Retrieved from http://www. hea. ie/en/publications/2016, 2016.

[23] J. Lockwood, A. Mooney, and S. Bergin. A neurofeedback system to promote learner engagement. (1):1-12, 2016.

[24] H. Lortie-Forgues and M. Inglis. Rigorous large-scale educational rcts are often uninformative: Should we be concerned? Educational Researcher, 48(3):158-166, 2019.

[25] E. Lovell. Promoting constructive mindsets for overcoming failure in computer science education. Proceedings of the tenth annual conference on International computing education research - ICER '14, pages 159-160, 2014.

[26] A. Luxton-Reilly. Learning to program is easy. Proceedings of the 2016 ACM Conference on Innovation and Technology in Computer Science Education, pages 284-289, 2016.
[27] J. A. Mangels, B. Butterfield, J. Lamb, C. Good, and C. S. Dweck. Why do beliefs about intelligence influence learning success? a social cognitive neuroscience model. Social cognitive and affective neuroscience, 1(2):75-86, 2006.

[28] D. I. Miller. When do growth mindset interventions work? Trends in cognitive sciences, 23(11):910-912, 2019.

[29] K. Muenks, E. Canning, D. Green, S. Zirkel, J. Garcia, and M. Murphy. Does my professor think my ability can change? students' perceptions of their stem professors' mindset predict in-class psychological experiences. Manuscript under review, 2018

[30] L. Murphy and L. Thomas. Dangers of a fixed mindset: implications of selftheories research for computer science education. ACM SIGCSE Bulletin, 40(3):271-275, 2008

[31] K. Nolan, A. Mooney, and S. Bergin. Facilitating student learning in Computer Science : large class sizes and interventions. International Confernce on Engaging Pedagogy, 2015.

[32] D. Paunesku, G. M. Walton, C. Romero, E. N. Smith, D. S. Yeager, and C. S. Dweck. Mind-set interventions are a scalable treatment for academic underachievement. Psychological science, 26(6):784-793, 2015.

[33] K. Quille and S. Bergin. Programming: Factors that influence success revisited and expanded. In International Conference on Enguaging Pedagogy (ICEP), $3 r d$ and 4th December, College of Computing Technology, Dublin, Ireland, 2015.

[34] K. Quille and S. Bergin. Does Scratch improve self-efficacy and performance when learning to program in C\#? An empirical study. In International Conference on Enguaging Pedagogy (ICEP), 2016.

[35] K. Quille and S. Bergin. Programming: Further factors that influence success. Psychology of Programming Interest Group (PPIG), 7th to 10th Spetember, University of Cambridge, 2016.

[36] K. Quille and S. Bergin. Programming : Predicting Student Success Early in CS1 . A Re-validation and Replication Study. In Proceedings of the 23rd Annual ACM Conference on Innovation and Technology in Computer Science Education (ITiCSE'18), ITiCSE '18, New York, NY, USA, 2018. ACM.

[37] K. Quille, S. Bergin, and A. Mooney. Press\#, a web-based educational system to predict programming performance. International fournal of Computer Science and Software Engineering (IFCSSE), 4(7):178-189, 2015.

[38] K. Quille, S. Bergin, and K. Quille. CS1 : how will they do ? How can we help ? A decade of research and practice research and practice. Computer Science Education, 29(2-3):254-282, 2019.

[39] K. Quille, N. Culligan, and S. Bergin. Insights on gender differences in cs1: A multi-institutional, multi-variate study. In Proceedings of the 2017 ACM Conference on Innovation and Technology in Computer Science Education, ITiCSE '17, pages 263-268, New York, NY, USA, 2017. ACM.

[40] K. Quille, R. Faherty, S. Bergin, and B. A. Becker. Second level computer science: The irish k-12 journey begins. In Proceedings of the 18th Koli Calling International Conference on Computing Education Research, Koli Calling '18, New York, NY, USA, 2018. Association for Computing Machinery.

[41] J. B. Sarrasin, L. Nenciovici, L. M. B. Foisy, G. Allaire-Duquette, M. Riopel, and S. Masson. Effects of teaching the concept of neuroplasticity to induce a growth mindset on motivation, achievement, and brain activity: A meta-analysis. Trends in Neuroscience and Education, 12(January):22-31, 2018.

[42] N. Sigurdson and A. Petersen. An exploration of grit in a cs1 context. In Proceedings of the 18th Koli Calling International Conference on Computing Education Research, page 23. ACM, 2018.

[43] B. Simon, B. Hanks, L. Murphy, S. Fitzgerald, R. McCauley, L. Thomas, and C. Zander. Saying isn't necessarily believing: Influencing self-theories in computing. Proceeding of the fourth international workshop on Computing education research, pages 173-184, 2008.

[44] D. Traynor, S. Bergin, and J. P. Gibson. Automated Assessment in CS1. Ace '06, pages 223-228, 2006

[45] B. L. Welch. The generalization ofstudent's' problem when several different population variances are involved. Biometrika, 34(1/2):28-35, 1947.

[46] D. Yeager, G. Walton, and G. L. Cohen. Addressing achievement gaps with psychological interventions. Phi Delta Kappan, 94(5):62-65, 2013.

[47] D. S. Yeager, R. E. Dahl, and C. S. Dweck. Why interventions to influence adolescent behavior often fail but could succeed. Perspectives on Psychological Science, 13(1):101-122, 2018

[48] D. S. Yeager, C. Romero, D. Paunesku, C. S. Hulleman, B. Schneider, C. Hinojosa, H. Y. Lee, J. O'Brien, K. Flint, A. Roberts, et al. Using design thinking to improve psychological interventions: The case of the growth mindset during the transition to high school. Fournal of educational psychology, 108(3):374, 2016.

[49] D. S. Yeager, G. M. Walton, S. T. Brady, E. N. Akcinar, D. Paunesku, L. Keane, D. Kamentz, G. Ritter, A. L. Duckworth, R. Urstein, et al. Teaching a lay theory before college narrows achievement gaps at scale. Proceedings of the National Academy of Sciences, 113(24):E3341-E3348, 2016. 